[Agr. Biol. Chem., Vol. 34, No. 5, p. 784 789, 1970]

\title{
Studies on BHC lsomers and their Related Compounds
}

\author{
Part I. Stepwise Synthesis of 3,4,5,6-Tetrachlorocyclohexene-1 \\ (BTC) Isomers
}

\author{
By Norio Kurihara, Yuzuru Sanemitsu, Tomio Kimura, \\ Masaharu KobayashI and Minoru NAKaJIMA \\ Department of Agricultural Chemistry, Kyoto University, \\ Kyoto, Japan \\ Received October 9, 1969
}

$\beta$-BTC $(3,4 / 5,6),{ }^{11} \gamma$-BTC $(3,4,6 / 5)$, and $\varepsilon$-BTC $(3,4,5 / 6)$ were synthesized from $\alpha$-BTC $(3,6 / 4,5)$ by stepwise routes.

3,4,5,6-Tetrachlorocyclohexene-1 (BTC) isomers ${ }^{21}$ are important intermediary compounds for synthesizing $\mathrm{BHC}$ isomers and their analogs. Especially $\gamma$-BTC $(3,4,6 / 5)$ is important, since it affords $\gamma$-BHC $(1,2,4,5 / 3,6)$ (lindane) on chlorination, ${ }^{2}$ and, on several addition reactions, will afford analogous compounds of the same configuration as that of lindane, which should be a very useful group of compounds for investigation on their structure-insecticidal (physiological) activity relationships.

Partial additive chlorination ${ }^{2)}$ of benzene yields BTC isomers as oily products, from which all of the possible stereoisomers, except all cis-isomer, can be isolated in crystalline states. The main product is $\alpha$-BTC $(3,6 / 4,5)$, and the other isomers are obtained in low yields after laborious chromatographic separation.

In this report, we will describe the stepwise synthesis of $\beta$-, $\gamma$-, and $s$-isomers from the

1) The configuration of the compounds is indicated by fractional notation whereby numerals in the numerator denote halogen or other groups (not hydrogen) above the plane of the ring whilst numerals in the denominator denote such substituents below that plane.

2) G. Calingaert, M. E. Griffing, E. R. Kerr, A. J. Kolka and H. D. Orloff, J. Am. Chem. Soc., 73, 5224 (1951); H. D. Orloff, A. J. Kolka, G. Calingaert, M. E. Grifing and E. R. Kerr, ibid., 75, 4243 (1953).
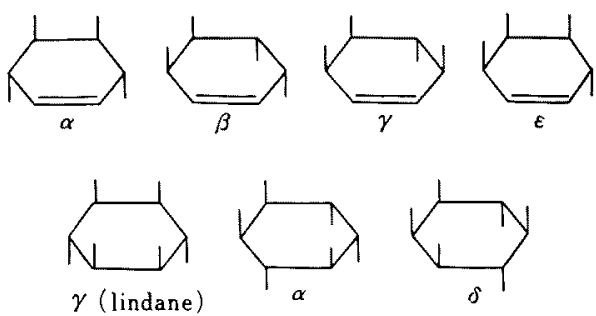

FIG. 1. Some of the BTC and BHC Isomers.

In the structural formulae, each racemic compound is shown by an arbitrarily chosen enantiomorphic form.

readily available $\alpha$-isomer of BTC.

\section{$\beta-B T C$}

$\alpha$-BTC was oxidized with permanganate in a neutral medium giving cis-glycol (I). ${ }^{3)} \mathrm{Al}$ kaline treatment of the glycol gave an epoxide (II) $)^{4}$ as a result of dehydrochlorination. The remaining hydroxyl group was converted to the chlorine atom by treating with sulfuryl chloride in pyridine-chloroform. ${ }^{51}$ Thionyl

3) M. Nakajima, I. Tomida and S. Takei, Chem. Ber., 92, 163 (1959):

4) N. Kurihara, T. Kurokawa, H. Naka and M. Nakajima, Agr. Biol. Chem., 33, 1186 (1969).

5) P. D. Bragg, J. K. N. Jones and J. C. Turner, Can. J. Chem., 37, 1412 (1959). 


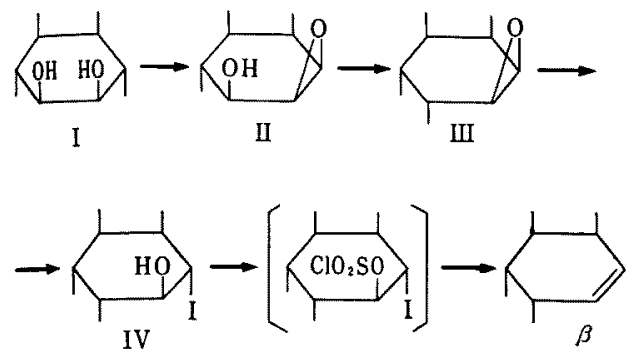

FIG. 2. Synthesis of $\beta$-BTC.

chloride or some other chlorinating reagents failed to afford the same product in a good yield.

The tetrachloro-compound (III) thus obtained was dissolved in alcohol and mixed with concentrated HI solution, which cleaved the epoxide giving an iodohydrin (IV). Sulfuryl chloride treatment of the iodohydrin smoothly afforded $\beta$-BTC $(3,4 / 5,6)$.

In the step from II to III, chlorination of the hydroxyl group by sulfuryl chloride was proved to be accompanied by the Walden inversion. If not, the last reaction product would have been $\gamma$-BTC $(3,4,6 / 5)$.

In this last step affording $\beta$-BTG, sulfuryl chloride was used again. Probably, a chlorosulfonyl derivative was first formed. Since the chlorosulfonyloxy group is a highly electron attracting group, and the neighboring iodine is easily suffered by nucleophilic attack to release an electron pair, it is easily understood that the spontaneous 1,2-elimination of these groups occurred to give $\beta$-BTC. This reaction may be considered as a modification of the general method to obtain olefins from iodohydrins, that is, methanesulfonylation or tosylation followed by iodide treatment. $^{6)}$ For the compound IV, mesylation or tosylation reactions were tried, but no desired product was isolated.

6) N. F. Taylor and G. M. Riggs, J. Chem. Soc., 1963,5600 .
$\gamma-B T C$

(1) Riemschneider ${ }^{7 !}$ reported an ICl addition reaction on $\alpha$-BTC, and the properties of the products which were the isomers of pentachloromonoiodocyclohexane. This additon is considered to be ionic and transoidal, and the only possible structures of the products are $\mathrm{V}$ and VI.

We repeated his experiments and obtained two products. Their melting points were not completely corresponding to those in his report. Our products of $\mathrm{mp} 155^{\circ} \mathrm{C}$ (A) (31\%) and $\mathrm{mp} 120^{\circ} \mathrm{C}(\mathrm{B})(19 \%)$ might be corresponding to the products of $\mathrm{mp} 132^{\circ} \mathrm{C}$ and $\mathrm{mp} 120^{\circ} \mathrm{C}$ in Riemschneider's paper, respectively. One of these iodo-compounds was useful in preparing $\gamma$-BTC.

When heated with NaI in DMSO, ICl elimination occurred, and the compound $A$ gave only $\alpha$-BTC (50\% yield), but B gave $\alpha$-, $\beta$-, and $\gamma$-BTC. We followed the time course of the reaction of $B$ with the aid of gas chromatography. First, $\alpha$ - and $\beta$-BTC were formed and then $\gamma$-isomer appeared later. The optimal condition to obtain the $\gamma$-isomer ( $43 \%$ yield) was $3 \mathrm{hr}$ heating at $90^{\circ} \mathrm{C}$. Most probably, $\beta$-BTC first formed by 1,2-elimination was assumed to isomerize gradually to $\gamma$-isomer, and starting iodo-compound (B) should have the structural formula VI as shown, on the basis of trans-ICl elimination. More detailed study on the isomerization of BTC isomers are described in the following paper. $^{81}$

(2) As described above, isomerization among several isomers of BTG was suggested. When pure $\beta$-BTC was heated at $100^{\circ} \mathrm{C}$ for $6 \mathrm{hr}$ in polar solvents such as DMSO, DMF and ethyleneglycol, $\gamma$-BTC was obtained in about $45 \%$ yield. Since $\beta$-BTC was synthesized from $\alpha$-BTC as described before, this isomerization forms a route from $\alpha$-BTC to

7) R. Riemschneider and G. Mau, Chem. Ber., 90, 2713 (1957).

8) N. Kurihara, Y. Sanemitsu, Y. Tamura and M. Nakajima, Agr. Biol. Chem., 34, 790 (1970). 


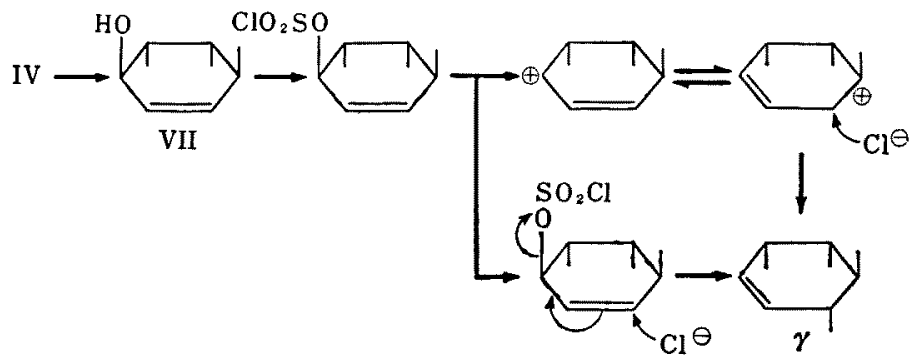

FIG. 3. Chlorination with Sulfuryl Chloride.
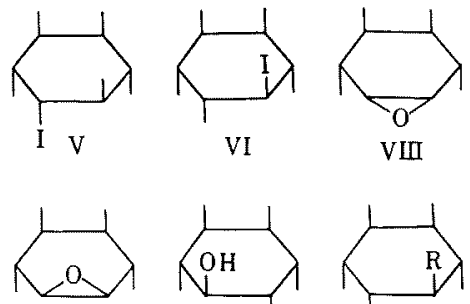

IX

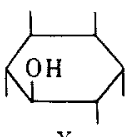

$\mathrm{x}$
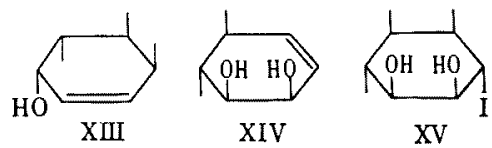

FIg. 4. Structural Formulae of Intermediates.

$\gamma$-BTC.

(3) The iodohydrin (IV), which was prepared as an intermediate in the synthesis of $\beta$-BTC, was heated with $\mathrm{NaI}$ in DMSO. Elimination of $\mathrm{ICl}$ occurred affording a monohydroxy-cyclohexene derivative $((3,6 / 4,5)-3$ hydroxy-4, 5, 6-trichlorocyclohexene-1) (VII). Treatment of this alcohol with sulfuryl chloride or thionyl chloride gave $\gamma$-BTC or the mixture of $\gamma$ - and $\beta$-isomer, respectively. In this last step producing $\gamma$-BTC, several mechanisms are possible involving $\mathrm{S}_{\mathrm{N}} 2^{\prime}$ and $\mathrm{S}_{\mathrm{N}} 1$ with allylic rearrangement as shown in Fig. 3. Beta-isomer formation can be explained by $\mathrm{S}_{\mathrm{N}} \mathrm{i}^{\prime}$ and/or $\mathrm{S}_{\mathrm{N}} \mathrm{l}$ mechanism.

(4) Chromic acid oxidation of $\alpha$-BTC gave reportedly an epoxide. ${ }^{91}$ Careful purification of the products revealed that there were two isomers of epoxide ( $\mathrm{mp} 90^{\circ} \mathrm{C}$ and $\mathrm{mp} 143^{\circ} \mathrm{C}$ ) involved. In relation to the neighboring chlorines each of them should be, either cis(VIII), or trans-epoxide (IX). When the high melting epoxide was cleaved with conc. HCl, it gave a pentachlorocyclohexanol which was identical with that (X) from $\beta$-BTC epoxide (III). The configuration of this chlorohydrin (X) is as illustrated in the structural formula, so that the starting epoxide should be transtype (IX).

The low melting epoxide, which was a prevailing product, should be cis-type (VIII), giving another chlorohydrin. ${ }^{91}$ Its structure should be XI.

In this chromic acid oxidation, ${ }^{101}$ the cisepoxide (VIII) formation was prevailing. This is explained by the easy attack of the double bond by chromic acid from the back side of allylic chlorine, and the succeeding back side attack of the newly induced group by hydroxyl oxygen (Fig. 5).

Cis-epoxide (VIII) was treated with HI affording an iodohydrin (XII), which in turn was treated with NaI in DMSO. Thus obtained hydroxycyclohexene derivative $((3,4 / 5$, 6-3-hydroxy-4,5,6-trichlorocyclohexene-1)(XIII)

9) S. Takei, M. Nakajima and I. Tomida, Chem Ber., 89, 263 (1956).

10) H. O. House, "Modern Synthetic Reactions," W. A. Benjamin Inc., New York and Amsterdam, 1965, pp. 96 99 . 


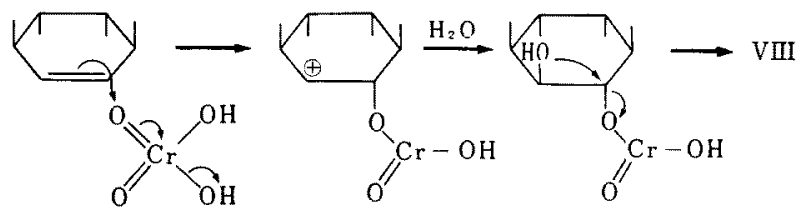

FIG. 5. Epoxidation of $\alpha-\mathrm{BTC}$ with $\mathrm{CrO}_{3}$.

was reacted with sulfuryl chloride. $r$-BTC was obtained in $80 \%$ yield.

\section{$\varepsilon-B T C$}

The epoxide (II), which was an intermediate in the conversion of $\alpha$-BTC to $\beta$-BTC, was treated with $\mathrm{HI}$ in aqueous methanol. The main product was an unsaturated glycol retaining two chlorine atoms in the molecule. The structure should be XIV as illustrated.

Probably $\mathrm{I}^{-}$ion in the reaction medium attacked the iodine atom in the possible intermediate $(\mathrm{XV})$. Since the iodine and the neighboring chlorine atom were situating trans-diaxially, ICI elimination in XV should occur smoothly.

The sulfuryl chloride treatment of XIV gave $\varepsilon$-BTC in a low yield $(\sim 10 \%)$ accompanied by $\delta$-BHC. The latter seemed to have formed by chlorine addition to $\varepsilon$-BTC. The preparation of $\varepsilon$-BTG by this route is not practical because of its low yield.

\section{Conclusive remarks}

Beta- and $\gamma$-isomers were synthesized from $\alpha$-BTC by stepwise reactions in satisfactory yields. The overall yield of $\beta$-BTC from $\alpha$ BTC was about $36 \%$, and in the best method (No. 3) of $r$-BTC synthesis, the overall yield from $\alpha$-BTC was about $33 \%$. This preparative method of $\gamma$-BTC will be used in our future works on the synthesis of $\gamma-\mathrm{BHC}$ analogs.

$\varepsilon$-BTC was also synthesized from $\alpha$-BTC in a low yield. For obtaining this isomer, the purification of the oily product resulting from partial additive chlrination of benzene might be a better method.

\section{EXPERIMENTAL}

Melting points were uncorrected. IR spectra were recorded with a Shimadzu AR-275 spectrophotometer. Gas chromatography (GLC) was run with a Yanagimato GC-5DH equipped with an electron capture detector. The column was a U-shaped stainless steel tube $(2.25 \mathrm{~m}=0.75 \mathrm{~m} \times 3)(\phi 3 \mathrm{~mm})$ packed with neopentyl glycol succinate (1.5\%) coated on chromosorb W $(60 \sim 80 \mathrm{mesh})$, or with SE-30 (5\%) coated on chromosorb W (80 $100 \mathrm{mesh})$, and the temperature was $150^{\circ} \mathrm{C}$. The flow rate of carrier helium gas at the inlet was $15 \mathrm{cc} / \mathrm{min}$. For thin-layer chromatography (TLC), Merck silica gel $G$ was used as an adsorbent, and $n$-hexane/chloroform was the solvent. The spraying reagent was $1 \%$ alcoholic o-toluidine solution. Spots were visible after irradiation with an UV lamp.

\section{$\beta-B T C$ epoxide (III)}

Sulfuryl chloride treatment of monohydroxy-compound(II). Monohydroxy-compound (II) ( $1 \mathrm{~g}$ ) was dissolved in chloroform-pyridine $(6 \mathrm{ml}$ and $1 \mathrm{ml})$, and sulfuryl chloride $(1 \mathrm{ml})$ was added slowly under ice-cooling and stirring. After $3 \mathrm{hr}$ ' stirring at room temperature, the reaction mixture was poured into ice-water. From the chloroform extract of the mixture, a crystalline mass ( $900 \mathrm{mg}, 82 \%$ ) was obtained. Recrystallized from $n$-hexane, mp $78^{\circ} \mathrm{C}$. Anal. Found: C, $30.87 ; \mathrm{H}$, 2.73 ; Calcd. for $\mathrm{C}_{6} \mathrm{H}_{6} \mathrm{OCl}_{4}: \mathrm{C}, 30.51 ; \mathrm{H}, 2.55 \%$.

$\beta-B T C$ iodohydrin (IV). Epoxide (III) (1 g) was dissolved in ethanol $(18 \mathrm{ml})$, and conc. HI solution $(3 \mathrm{ml})$ was added under ice-cooling and stirring. HI solution $(1.5 \mathrm{ml})$ was added at one hour intervals, and $9 \mathrm{ml}$ in total of the solution was added. After additional $2 \mathrm{hr}$ ' stirring, the mixture was poured into saturated $\mathrm{NaCl}$ aqueous solution, and ether extraction followed. From the extract, crude crystals of IV $(1.35 \mathrm{~g}, 88 \%)$ were obtained. Recrystallized from $n$ hexane-ethanol, $\mathrm{mp} 127^{\circ} \mathrm{C}$. Anal. Found: C, 20.02; $\mathrm{H}, 2.06$. Calcd. for $\mathrm{C}_{6} \mathrm{H}_{7} \mathrm{OCl}_{4} \mathrm{I}: \mathrm{C}, 19.89 ; \mathrm{H}, 1.92 \%$. 
3-BTC. Iodohydrin (IV) (500 mg) was dissolved in chloroform-pyridine $(2 \mathrm{ml}$ and $1 \mathrm{ml})$, and to the solution sulfuryl chloride $(1 \mathrm{ml})$ was slowly added under ice-cooling and stirring. After the addition, stirring was continued for $3 \mathrm{hr}$. The reaction mixture was poured into ize-water, and extracted with chloroform to give crude crystals of $\beta$-BTC $(240 \mathrm{mg}, 80 \%)$. Recrystallized from $n$-hexane, $\mathrm{mp} 80^{\circ} \mathrm{C}$. Identified with an authentic specimen by mixed melting point determination and IR spectra. Anal. Found: C, 33.03; $\mathrm{H}, 2.82$. Calcd. for $\mathrm{C}_{6} \mathrm{H}_{6} \mathrm{Cl}_{4}: \mathrm{C}, 32.73, \mathrm{H}$, $2.73 \%$.

ICl addition products ( $V$ and $V I$ ) of $\alpha-B T C$. A mixture of $\alpha$-BTC (5.5g), iodine $(0.5 \mathrm{~g})$ and iodine chloride ( $4 \mathrm{~g}$ ) was heated in an evaporation dish on a water bath at $40^{\circ} \mathrm{C}$ for $2 \mathrm{hr}$. Heating was discontinued after raising the temperature to $100^{\circ} \mathrm{C}$ slowly, and after cooling down to room temperature, the mixture was extracted with chloroform. The chloroform layer was washed with $0.1 \mathrm{~N} \mathrm{Na}_{2} \mathrm{~S}_{2} \mathrm{O}_{3}$, dried over $\mathrm{Na}_{2} \mathrm{SO}_{4}$, and then evaporated to dryness. A crude mixture of the $\mathrm{ICl}$ addition compounds $(7.2 \mathrm{~g})$ was obtained. Recrystallization from chloroform, and then from methanol. $\mathrm{V}(3 \mathrm{~g}, 31 \%)$ of $\mathrm{mp} 155^{\circ} \mathrm{C}$ and VI $(1.8 \mathrm{~g}$, 19.8) of $\mathrm{mp} 120^{\circ} \mathrm{C}$ were obtained. Anal. Found (V): C, $18.85 ; \mathrm{H}, 1.67$. (VI): C, 19.09; H, 1.79. Calcd. for $\mathrm{C}_{6} \mathrm{H}_{3} \mathrm{Cl}_{5} \mathrm{I}: \mathrm{C}, 18.85 ; \mathrm{H}, 1.58 \%$.

$\gamma$-BTC from $(1,2,5 / 3,4,6)$-5-iodo-1,2,3,4,6-pentachlorocyclohexane (VI). A mixture of iodo-compound VI (100 mg) and Nal (45 mg) was dissolved in DMSO $(2 \mathrm{ml})$, and heated at $90^{\circ} \mathrm{C}$ for $3 \mathrm{hr}$. After pouring into ice-water, the mixture was extracted with ether, and the ether extract was dried with $\mathrm{Na}_{2} \mathrm{SO}_{4}$ and evaporated to afford a yellow oil $(80 \mathrm{mg})$. Partition chromatography with a column of silicic acid $(15 \mathrm{~g})$, nitromethane $(8 \mathrm{ml})$ and $n$-hexane $(30 \mathrm{ml})$ afforded $\alpha$ BTC ( $8 \mathrm{mg})$, and $\gamma$-BTC $(25 \mathrm{mg}, 4306), \mathrm{mp} 87 \sim 88^{\circ} \mathrm{C}$. They were identified by means of GLC and IR spectra. Anal. Found $\alpha$-BTC: C, 32,70; H, 2.71. $\gamma$-BTC: $\mathrm{C}, 32.70 ; \mathrm{H}, 2,69$. Calcd. for $\mathrm{C}_{6} \mathrm{H}_{6} \mathrm{Cl}_{4}: \mathrm{C}, 32.73$; H, $2.73 \%$.

$\gamma$-BTC from $\beta$-BTC. $\quad \beta$-BTC $(100 \mathrm{mg})$ was dissolved in DMSO $(2 \mathrm{ml})$ and heated at $100^{\circ} \mathrm{C}$ for $5 \sim 6 \mathrm{hr}$. The reaction mixture was poured into ice-water and extracted with ether. After drying, ether was evaporated to afford syrupy residue. Partition chromatography was run on a column of silicic acid $(10 \mathrm{~g})$, nitromethane $(4 \mathrm{ml})$ and $n$-hexane $(20 \mathrm{ml})$. $r$-BTC
(45 mg, 45\%) was obtained as colorless crystals, mp $90 \sim 91^{\circ} \mathrm{C}$. Anal. Found: C, 32.71; H, 3.04. Calcd. for $\mathrm{C}_{6} \mathrm{H}_{6} \mathrm{Cl}_{4}: 32.73 ; \mathrm{H}, 2.73 \circ$.

(3,6/4,5)-3-Hydroxy-4, 5,6-trichlorocyclohexene-1(VII). The iodohydrin (IV) ( $3 \mathrm{~g}$ ) was heated in DMSO $(20 \mathrm{ml})$ with $\mathrm{NaI}(1.5 \mathrm{~g})$ at $60^{\circ} \mathrm{C}$ for $48 \mathrm{hr}$. The mixture was poured into ice-water and stirred for " while followed by ether extraction and washing with $0.1 \mathrm{~N}$ $\mathrm{Na}_{2} \mathrm{~S}_{2} \mathrm{O}_{3}$. The ether extract was dried and evaporated to afford a syrup, which was crystallized from chloroform. VII $(1.65 \mathrm{~g}, 95 \%)$ of $\mathrm{mp} 66 \sim 67^{\circ} \mathrm{C}$ was obtained. Anal. Found: C, 35.45; $\mathrm{H}, 3.56$. Calcd. for $\mathrm{C}_{6} \mathrm{H}_{7} \mathrm{OCl}_{3}$ : C, $35.70 ; \mathrm{H}, 3.45 \%$.

r-BTC from VII. (1) With sulfuryl chloride: VII $(100 \mathrm{mg})$ was dissolved in chloroform $(3 \mathrm{ml})$ and pyridine $(0.2 \mathrm{ml})$, and sulfuryl chloride $(0.2 \mathrm{ml})$ was slowly added under cooling. The mixture was stirred for additional $3 \mathrm{hr}$ at room temperature and poured into ice water. Chloroform extraction gave crude crystals (76 mg, 76\%) of $\gamma$-BTC. Recrystallized from $n$-hexane, mp $88 \sim 89^{\circ} \mathrm{C}$. Anal. Found: C, 32.62; H, 2.60. Calcd. for $\mathrm{C}_{6} \mathrm{H}_{6} \mathrm{Cl}_{4}: \mathrm{C}, 32.73 ; \mathrm{H}, 2.73 \%$.

(2) With thionyl chloride: VII $(100 \mathrm{mg})$ was dissolved in chloroform $(3 \mathrm{ml})$ and pyridine $(0.07 \mathrm{ml})$, and thionyl chloride $(0.036 \mathrm{ml})$ was added slowly and stirred for $3 \mathrm{hr}$ at room temperature. Then, pyridine $(0.07 \mathrm{ml})$ and thionyl chloride $(0.036 \mathrm{ml})$ were added, and stirring was continued for one more hour. After pouring into ice-water, extraction with chloroform afforded a syrup ( $80 \mathrm{mg})$, which was partitioned with a silicic acid column $(7 \mathrm{~g}$; and nitromethane $2.8 \mathrm{ml}$, $n$-hexane $14 \mathrm{ml}) . \quad \beta$-BTC $(10 \mathrm{mg}, 10 \%)$, and $\gamma$-BTC $(60 \mathrm{mg}, 60 \%)$ were obtained. Anal. Found $\beta-\mathrm{BTC}$ : C, $32.50 ; \mathrm{H}, 2.50 ; \gamma$-BTC: C, 32.58; H, 2.60. Calcd. for $\mathrm{C}_{6} \mathrm{H}_{6} \mathrm{Cl}_{4}: \mathrm{C}, 32.73 ; \mathrm{H}, 2.73 \%$.

$\alpha$-BTC epoxide (VIII and IX). $\alpha$-BTC $(15 \mathrm{~g})$ was heated with $\mathrm{CrO}_{3}(12 \mathrm{~g})$ in glacial acetic acid $(120 \mathrm{ml})$ containing a little amount of water at $90 \sim 100^{\circ} \mathrm{C}$. Exothermic reaction occurred, and the mixture boiled vigorously by itself. After about $10 \mathrm{~min}$, when the reaction became calm, heating was stopped and the mixture was poured into ice-water with stirring. Crude crystals appeared and they were purified by absorption chromatography. The column was packed with silicic acid $(60 \mathrm{~g})$ and the solvent was a mixture of chloroform and $n$-hexane $(1: 3 \mathrm{v} / \mathrm{v})$. Obtained were VIII $(2 \mathrm{~g}, 16 \%)$ of $\mathrm{mp} 90^{\circ} \mathrm{C}, 91 \mathrm{IX}(0.2 \mathrm{~g}, 0.2 \%)$ of mp $142 \sim 43^{\circ} \mathrm{C}$, and unreacted $\alpha$-BTC $(12 \mathrm{~g})$ Anal. 
Found VIII: $\mathrm{C}, 30.64 ; \mathrm{H}, 2.66 . \mathrm{IX}: \mathrm{C}, 30.50 ; \mathrm{H}$, 2.52. Calcd. for $\mathrm{C}_{6} \mathrm{H}_{6} \mathrm{Cl}_{4} \mathrm{O}: \mathrm{C}, 30.54 ; \mathrm{H}, 2.56 \%$.

(1,2,5/3,4,6)-1-Hydroxy-2,3,4,5,6-pentachlorocyclohexane (XI). Epoxide (VIII) (100 mg) was heated in ethanol (3ml) with conc. $\mathrm{HCl}(2 \mathrm{ml})$ under reflux for $4 \mathrm{hr}$. Evaporation of the solvent gave a syrup, which was crystallized from $n$-hexane. Yield $120 \mathrm{mg}, 100 \%$, $\mathrm{mp} 120 \sim 21^{\circ} \mathrm{C} .{ }^{91}$ Anal. Found: C, 26.62; H, 2.79. Calcd. for $\mathrm{C}_{6} \mathrm{H}_{7} \mathrm{Cl}_{5} \mathrm{O}: \mathrm{C}, 26.45 ; \mathrm{H}, 2.59 \%$.

\section{$(I, 2,5 / 3,4,6)-5$-Hydroxy-1,2,3,4,6-pentachlorocyclohexane}

(l) From $\alpha$-BTC epoxide (IX). From epoxide IX (100 mg) chlorohydrin (X) (118 mg, 9796$)$ of $\mathrm{mp} 108^{\circ} \mathrm{C}$ was obtained by the method just described above. Anal. Found: C, $26.40 ; \mathrm{H}, 2.53$. Calcd. for $\mathrm{C}_{6} \mathrm{H}_{7} \mathrm{Cl}_{5} \mathrm{O}$ : C, $26.45 ; \mathrm{H}, 2.59 \%$.

(2) From $\beta$-BTC epoxide (III). From epoxide (III) (100 mg), chlorohydrin (X) (110 mg, 95\%) of $\mathrm{mp}$ $108^{\circ} \mathrm{C}$ was obtained and identified with the above mentioned compound by IR spectra and the mixed melting point. Anal. Found: C, 26.40; H, 2.50. Calcd. for $\mathrm{C}_{6} \mathrm{H}_{7} \mathrm{Cl}_{5} \mathrm{O}: \mathrm{C}, 26.45 ; \mathrm{H}, 2.59 \%$.

$(1,2,5 / 3,4,6)$-1-Hydroxy-6-iodo-2,3,4,5-tetrachlorocyclohexane $(X I I)$. Epoxide (VIII) (100 mg) in acetic acid $(0.3 \mathrm{ml})$ was stirred under cooling, to which $\mathrm{HI}$ solution $(0.4 \mathrm{ml})$ was added slowly. At $30 \mathrm{~min}$ intervals HI solution $(0.2 \mathrm{ml})$ was added, and in total $0.6 \mathrm{ml}$ of the solution was added. After stirring for additional $30 \mathrm{~min}$, the mixture was poured into sat. $\mathrm{NaCl}$ solution and extracted with ether. The ether extract afforded crude crystals $(70 \mathrm{mg}, 84 \%)$ of $\mathrm{mp}$ $117 \sim 18^{\circ} \mathrm{C}$.

(3, 4/5,6)-3-Hydroxy-4,5,6-trichlorocyclohexene-1 (XIII). lodohydrin (XII) $(100 \mathrm{mg})$ was heated in DMSO $(3 \mathrm{ml})$ with $\mathrm{NaI}(50 \mathrm{mg})$ at $100^{\circ} \mathrm{C}$ for $6 \mathrm{hr}$. After pouring into ice-water, the mixture was extracted with ether. The ether extract was washed with $0.1 \mathrm{~N} \mathrm{Na} \mathrm{Na}_{2} \mathrm{O}_{3}$ and dried. It was evaporated to afford a syrup ( $40 \mathrm{mg}$, $80 \%$ ) of XIII. Anal. Found: C, 35.40; H, 3.20. Calcd. for $\mathrm{C}_{6} \mathrm{H}_{7} \mathrm{Cl}_{4} \mathrm{O} ; \mathrm{C}, 35.70 ; \mathrm{H}, 3.45 \%$.
r-BTC from XIII. Mono-ol (XIII) (100 mg) was dissolved in chloroform-pyridine $(3 \mathrm{ml}$ and $0.2 \mathrm{ml})$. Under cooling, sulfuryl chloride $(0.2 \mathrm{ml})$ was added slowly, and the mixture was stirred at room temperature for $3 \mathrm{hr}$. After pouring into ice-water, the mixture was extracted by chloroform to afford crude crystals $(80 \mathrm{mg}, 80 \%)$ of $\mathrm{mp} 88 \sim 90^{\circ} \mathrm{C}$. Anal. Found: C, 32.45; H, 2.59. Calcd. for $\mathrm{C}_{6} \mathrm{H}_{6} \mathrm{Cl}_{4}: \mathrm{C}, 32.73 ; \mathrm{H}$, $2.73 \%$

(3, 4,6/5)-3,4-Dihydroxy-5,6-dichlorocyclohexene-1 (XIV). Monohydroxy-epoxide (II) ( $1 \mathrm{~g})$ was dissolved in methanol $(3.5 \mathrm{ml})$, and HI solution $(4 \mathrm{ml})$ was slowly added under cooling and stirring. Every $30 \mathrm{~min} \mathrm{HI}$ solution $(2 \mathrm{ml})$ was added to the stirred mixture, and in total $12 \mathrm{ml}$ of $\mathrm{HI}$ solution was added. After stirring at room temperature for additional $30 \mathrm{~min}$, the reaction mixture was poured into saturated $\mathrm{NaCl}$ solution, and the whole mixture was extracted with ether to afford crude crystals (690 mg, 84\%). Recrystallized from benzene, mp $102^{\circ} \mathrm{C}$. Anal. Found: C, 39.56; $\mathrm{H}, 4.43$. Calcd. for $\mathrm{C}_{6} \mathrm{H}_{8} \mathrm{Cl}_{2} \mathrm{O}_{2}: \mathrm{C}, 39.37$, $\mathrm{H}, 4.37 \%$.

$E-B T C$ and $\delta$-BHC from XIV. Dihydroxy-compound (XIV) $(250 \mathrm{mg})$ was treated in chloroform $(10 \mathrm{ml})$ and pyridine $(1 \mathrm{ml})$ with sulfuryl chloride $(1 \mathrm{ml})$ under cooling and stirring. After $2 \mathrm{hr}^{\prime}$ stirring at room temperature, the mixture was poured into ice-water and extracted with chloroform to afford a syrup (170 mg). Partition chromatography with a column made of silicic acid $(20 \mathrm{~g})$, nitromethane $(8 \mathrm{ml})$ and $n$-hexane $(40 \mathrm{ml})$ was performed by employing $n$ hexane saturated with nitromethane as a mobile phase. $\varepsilon$-BTC $(20 \mathrm{mg})$ of $\mathrm{mp} 102.5^{\circ} \mathrm{C}$ and $\delta$-BHC $(15 \mathrm{mg})$ of $\mathrm{mp} 138^{\circ} \mathrm{C}$ were obtained and identified by means of GLC and IR spectra. Anal. Found $\varepsilon$-BTC: C, 33.03; $\mathrm{H}$, 2.83. Calcd. for $\mathrm{C}_{6} \mathrm{H}_{6} \mathrm{Cl}_{4}: \mathrm{C}, 32.73 ; \mathrm{H}, 2.73 \%$. $\delta$-BHC: C, 25.02; $\mathrm{H}, 2.19$. Calcd. for $\mathrm{C}_{6} \mathrm{H}_{6} \mathrm{Cl}_{6}: \mathrm{C}$, $24.77 ; \mathrm{H}, 2.06 \%$.

Acknowledgment. We are much indebted to Professor Tetsuo Mitsui and his associates for microanalyse: 